\title{
The Role of Faculty Mentoring in Improving Retention and Completion Rates for Historically Underrepresented STEM Students
}

\author{
Dr. Kelli L. Chelberg ${ }^{1} \&$ Dr. Lisa B. Bosman ${ }^{2}$ \\ ${ }^{1}$ School of Education, College of Menominee Nation, Keshena, Wisconsin, USA \\ ${ }^{2}$ Purdue Polytechnic Institute, Purdue University, West Lafayette, Indiana, USA \\ Correspondence: Dr. Kelli Chelberg, School of Education, College of Menominee Nation, Keshena, Wisconsin, \\ United States of America. Email: kchelberg@ menominee.edu
}

Received: March 15, 2019

Accepted: April 5, 2019

Online Published: April 12, 2019

doi:10.5430/ijhe.v8n2p39

URL: https://doi.org/10.5430/ijhe.v8n2p39

\begin{abstract}
There is a growing recognition of the need for science, technology, engineering, and mathematics (STEM) workers who provide diverse perspectives enabling companies to keep up with the demands of the $21^{\text {st }}$-century workforce. Creating a diverse workforce requires improving access to STEM education for historically underrepresented students, including low-income students and first-generation students. However, significant challenges and barriers exist. The purpose of this paper is to showcase an innovative approach to mentoring historically underrepresented STEM students which integrates photovoice and photo-elicitation. This new approach in mentoring takes student participation one step further by asking students to document and share their lived experiences through photographs (e.g., photovoice). Then, photo-elicitation is used to further engage students in discussing what led to their subsequent empowerment in leveraging successes or overcoming barriers. The study was conducted with 19 participants who were primarily American Indian students attending a small college in Wisconsin, USA. The findings suggest students benefited from the mentoring program and perceived it as an enriching learning experience which aided in goal development, accountability, and an opportunity to learn more about strategies for student success. The implementation of this new approach and the results gathered from this study are important as they may inform educational leaders and postsecondary institutions serving historically underrepresented STEM students on supports and strategies that could be carried out on their campuses.
\end{abstract}

Keywords: undergraduate, American Indian, tribal college, participatory action research, culture, photovoice, photo-elicitation

\section{Introduction}

\subsection{Problem Identification}

The increased demand for science, technology, engineering, and mathematics (STEM) professionals has resulted in considerable focus and attention to the enrollment, persistence, and completion of STEM students at higher education institutions worldwide (Graham, Frederick, Byars-Winston, Hunter, \& Handelsman, 2013; Latz, 2015; Lichtenstein, Chen, Smith, \& Maldonado, 2014). Specifically, there is a growing recognition of the need for STEM workers who provide diverse perspectives enabling companies to keep up with the demands of the $21^{\text {st }}$-century workforce. Not surprisingly, creating a diverse workforce requires improving access to STEM education for historically underrepresented students, including low-income students and first-generation students (Dika, Pando, Tempest, Foxx, \& Allen, 2015; MacPhee, Farro, \& Canetto, 2013). Science and engineering employment statistics are dismal for historically underrepresented individuals. According to the National Science Foundation's Science and Engineering Indicators Report 2018, minorities including Hispanics, African Americans, and American Indian/Alaska Natives comprise $27 \%$ of the U.S. adult (21+) population, yet only make up $11 \%$ of workers employed in science and engineering occupations. From a higher education perspective, in 2015, the percentage of science and engineering bachelor's degrees awarded to minorities, including Hispanics, blacks, and American Indian/Alaska Natives, was only $22.5 \%$ and for women, 20.1\% (National Science Board, 2018). To add to this disparity, first-generation students are four times more likely to drop out of college before graduating (Engle \& Tinto, 2008). 


\subsection{Barriers and Challenges}

Research suggests there are a number of barriers preventing recruitment, retention, persistence, and completion in STEM (Johri \& Olds, 2014), which is multiplied when considering challenges commonly experienced by historically underrepresented students in STEM (Dika et al., 2015; MacPhee et al., 2013). Student identity and beliefs have a more significant impact on predicting student choice to enroll in STEM programs than student performance and competence level (Godwin, Potvin, Hazari, \& Lock, 2016). Furthermore, identity correlates with retention and persistence (Tonso, 2014). Unfortunately, the "chilly climate" often associated with STEM programs can lead to feelings of self-doubt, isolation, and questions of student belonging (Lichtenstein et al., 2014), which is reported more often by women and minorities. The lack of student belonging is thought to be a result of the absence of role models, limited faculty interaction, and lack of effective advising, which is cited as a common cause of attrition from STEM education and the STEM workforce (Lichtenstein et al., 2014). This lack of connection can lead to enrollment avoidance, transfer into non-STEM programs, or drop-outs before degree completion. As a result, there is a need to create an inviting environment for historically underrepresented students that promote student motivation for learning in STEM (Guillory \& M. Wolverton, 2008; R. M. Guillory \& M. Wolverton, 2008).

Another major challenge is inadequate access to career counseling and, therefore, lack of knowledge related to potential academic or career pathways (Sheppard, Antonio, Brunhaver, \& Gilmartin, 2014). This knowledge disparity is of particular importance to minority students who are frequently first-generation and low-income college students, resulting in a limited ability for parents to offer guidance and career advising. Furthermore, lack of curriculum reforms and limited change in teaching pedagogies are rampant in STEM disciplines (Tsui, 2007). Anecdotal evidence has shown that instructors tend to teach the way they were taught, commonly through the use of lecture, instead of utilizing evidence-based teaching methods which tend to be inclusive of all learners, such as experiential learning (Kolb, 1984). Lastly, a significant barrier to success in STEM is the inability for code-switching. Code-switching refers to one's ability to communicate with people of all audiences, in both professional terms and popular terms (Downey et al., 2006). These "soft skills" are of specific importance to STEM workers, who are often required to translate complex concepts and terms into information that can be consumed by multiple audiences. The literature goes on to suggest many other factors that contribute to challenges in higher education retention, including trouble in adapting to the academic community, cultural mismatch with student's upbringing, social isolation, family and personal issues, low self-esteem, and insufficient financial support (Huffman, 2001; Hunt \& Harrington, 2010; Keith, Stastny, \& Brunt, 2016). In order to overcome the barriers commonly faced by STEM students, and especially by historically underrepresented students, new student success strategies should be employed and analyzed for effectiveness in meeting learning outcomes, increasing student self-efficacy, providing a supportive environment, and promoting a perceived valuable learning experience.

\subsection{Mentoring in Higher Education}

Many researchers have identified mentoring as an essential strategy in assisting students of color in navigating the challenges of higher education (Crisp, Baker, Griffin, Lunsford, \& Pifer, 2017; Hund et al., 2018; Liou, Martinez, \& Rotheram-Fuller, 2016; Wilson et al., 2012). Providing students with access to both informal and formal mentoring has become a national priority as evidenced by the increased number of mentoring programs at postsecondary institutions (Crisp \& Cruz, 2009). Mentoring may be an effective strategy for addressing issues facing many colleges and universities today including increasing degree completion, reducing inequities in outcomes for minority students, and broadening participation in the STEM pipeline and workforce (Crisp et al., 2017; G. Crisp, V. L. Baker, K. A. Griffin, L. G. Lunsford, \& M. J. Pifer, 2017; Hund et al., 2018; Wilson et al., 2012). The impact of mentoring has long been considered to be a developmental and retention strategy for undergraduate education and one which has a positive impact on academic outcomes, social integration, and higher student self-esteem (Collings, Swanson, \& Watkins, 2014). There is mounting evidence that points to the need for both academic and psychosocial support for historically underrepresented students (Keith et al., 2016). Furthermore, many first-generation college students have limited knowledge of the higher education system and navigational skills needed to meet the rigorous requirements of postsecondary institutions (Flynn, Duncan, \& Jorgensen, 2012). Research suggests the use of mentoring as a pedagogical approach in addressing critical components needed for academic success in that being a part of a supportive environment is significant to student motivation, learning, and confidence in degree attainment (Jackson, Smith, \& Hill, 2003).

\subsection{Photovoice}

One way of capturing students' voices is through methods like photovoice. Photovoice is a participatory action research method and allows for participants to become co-researchers and promotes self-expression and reflection. 
Photographs provide powerful representations into the deeply personal and varied experiences of the photographer. The use of photography has always been used as a means of documenting and sharing daily-lived experiences and recently has emerged as a qualitative research tool (Hergenrather, Rhodes, Cowan, Bardhoshi, \& Pula, 2009). Photovoice, which was created by Wang and Burris (1997) as a means to empower women in the Yunnan province of China and was based on the belief that "problem-posing education starts with issues that people see as central to their lives" (p. 370). Through the process of photovoice participants are asked to think critically and reflect on their challenges (e.g., health issues, community challenges, and education barriers) to tell a story and become a potential catalyst for personal and community change. Photovoice has primarily been used in health research to empower marginalized individuals (Castleden \& Garvin, 2008) and is beginning to be utilized in educational contexts as well (Harkness \& Stallworth, 2013). Photovoice provides for an inclusive and flexible data collection process and allows participants the opportunity to increase their power within the project by photographing the variables of individual importance and concern (Hergenrather et al., 2009). The use of photovoice benefits participants as they document challenges and are empowered to communicate about issues impacting their lives (Agarwal, Moya, Naoko Yura, \& Seymour, 2015). In addition, photovoice allows participants the opportunity to construct learning about an issue of concern based on their own experiences and individual ideas (Hergenrather et al., 2009). Given the methodology employed, and the individualized nature of the research that has been completed using photovoice, many of the findings in this study are not meant to be generalizable, but to provide an understanding of the participant's experiences. The use of photography provides an opportunity for participants to document their everyday experiences in the places and spaces that they regularly (Minthorn \& Marsh, 2016). Furthermore, the use of visual images and constructed narratives reinforce the importance of listening to the voices and perspectives of participants to inform necessary changes in practice, policy, and procedures in postsecondary institutions.

Photo elicitation is an approach within qualitative inquiry that takes photovoice one step further in that participants are asked a series of questions that are intended to produce a more in-depth description of the photograph by the participant. Photo elicitation also allows participants to identify strategies that are self-driven, which then provides empowerment for persistence and goal completion. Providing participants, a space and opportunity to create and construct meaning of their experience through their own eyes (via a camera) and in their own words (via a narrative) through photo-elicitation benefits participants by encouraging them to identify perceived educational barriers, as well as eliciting deeper thinking regarding ways in which students can overcome difficult and complex circumstances. As a result, any resultant empowerment may lead to an increase in participants' belief in their ability to overcome perceived barriers to their educational goals (Tate et al., 2015). Photo elicitation can use a facilitated process called SHOWED to guide dialogue and discussion of the images. The SHOWED dialogue framework was rooted in the work of Paolo Freire and was inspired by his notion of empowerment education (Sahay, Thatcher, Núñez, \& Lightfoot, 2016). The SHOWED method is a structural guide to facilitate deeper thinking and discussion using specific prompts. The method consists of six open-ended questions that lead the participant to identify what the photograph represents, how it relates to their lives, and how they can become empowered by their new understanding. This participatory process can be used to further elicit participant's shared understanding of successes and barriers to their education resulting in an authentic understanding and empowerment. The methodology of photovoice and photo-elicitation are increasingly becoming a unique and flexible mode of inquiry to address a variety of community and cultural needs.

\subsection{Purpose and Research Questions}

Pursuing postsecondary education is a complex learning experience that entails navigating complex information capital components. This process requires navigational and informational skills, course advising, career counseling, and psychosocial skills. While these components are inextricably intertwined and critical to student success, the purpose of this research was to examine the impact the mentoring relationship as a source of efficacy, navigational, and informational capital has on student self-efficacy. While a growing body of research begins to explore student spaces and supports needed within that of formal education, there is limited research that "explores how space and place inform the educational experiences" of historically underrepresented students (Minthorn \& Marsh, 2016, p. 6). Also, many higher education institutions have attempted to increase recruitment, retention, and completion of underrepresented students in STEM through implementing student success strategies with commitment and investment in programs aimed at increasing access and equity to women, minorities, first generation, and low socio-economic status students. Much effort and consideration have been given to identifying the challenges and barriers faced by historically underrepresented students, low-income students, and first-generation students. However, the research has often been about and not with the student and subsequently from a deficit perspective. However, by including students as researchers allow for sharing of ideas and lived experiences, which provides for equitable 
contributions, shared decision-making, and ownership.

The purpose of this paper is to showcase an innovative approach to mentoring which integrates photovoice to help students better communicate their challenges and share student satisfaction results related to this new approach. The research questions addressed in this study are as follows: (1) How does participating in the mentoring contribute to student satisfaction? (2) How does participating in photovoice and photo-elicitation contribute to student satisfaction?

\section{Method}

\subsection{Participant Characteristics}

Participants were recruited from a small college in northern Wisconsin, U.S.A. during the Spring 2018 semester using a campus-wide email and was required to apply via an online form. All students were eligible to participate regardless of race or ethnicity, program affiliation, and credit status. However, preference was given to historically underrepresented students enrolled full-time in a STEM major. Twenty-five applicants applied and all were selected and notified by email of their acceptance and were asked to schedule an interview time to meet with the researcher, review the expectations, learn about the stipend $(\$ 1000)$, as well as to provide an opportunity for participants to ask questions and sign the IRB approved participant consent form. Twenty-two students interviewed and completed paperwork and gave consent and expressed a desire to participate in the project. A total of 19 undergraduate students completed the program. The demographic characteristics are reported in Table 1. All participants were enrolled full time and identify as a minority, female and/or STEM student.

Table 1. Demographic Characteristics of Participants

\begin{tabular}{lll}
\hline Characteristic & $n$ & $\%$ \\
\hline Gender & 9 & 47.4 \\
$\quad$ Male & 10 & 52.6 \\
$\quad$ Female & & \\
Age of Participants & 5 & 26.3 \\
$\quad$ 18-24 & 7 & 36.8 \\
$25-34$ & 3 & 15.8 \\
$35-44$ & 3 & 15.8 \\
$45-54$ & 1 & 5.3 \\
55-64 & 13 & \\
Ethnicity & 4 & 68.4 \\
$\quad$ American Indian & 2 & 21.1 \\
Caucasian & & 10.5 \\
Hispanic/Latino & 15 & \\
High School Diploma/GED & 4 & 21.1 \\
High School Diploma & & \\
General Education Diploma & 8 & 57.9 \\
Parents with a bachelor's degree & 11 & \\
Yes & &
\end{tabular}

\subsection{Intervention - Mentoring Program}

Participants were required to meet for eight mentor meetings throughout the semester. All participants were provided a Wi-Fi enabled, unlocked Smartphone; which included a 5-megapixel camera. At the conclusion of each mentoring meeting, participants were assigned to take four pictures based on a series of prompts (as shown in Appendix A). Two of the pictures were to represent barriers, and two were to represent the success and motivations related to them enrolling and persisting in college. In addition, participants were asked to write a one-sentence description for each picture. At their follow-up mentor meeting, participants met with a faculty mentor and were asked a series of 
questions to further elicit reflection on their successes and barriers to their education. As a result, a written narrative was co-constructed with their faculty mentor with the mentor typing as the participants reflected and shared their thoughts and understanding of the barrier or success that the picture represented. Once the narrative was complete, the narrative was read aloud to ensure the accuracy of participants' responses and for them to provide consent on the final version.

\subsection{Student Satisfaction Survey}

At the end of the semester and upon completion of the eight mentor meetings, photo submission, and written narratives, participants were sent an email containing a link to a student satisfaction survey. Once this final survey was complete, students received the stipend. At this time, participants were asked to reflect on the mentoring experience by responding to the following open-ended questions:

1. Identify at least three benefits that you have received from the mentoring program.

2. Identify at least three benefits you have received from your participation in taking pictures, writing statements and setting goals based on the photovoice prompts.

3. Identify at least one way to improve the mentoring program.

4. [College X] is thinking about making mentoring available to more students next semester. This would require recruiting additional faculty/staff mentors. What characteristics do you believe would make a good mentor?

5. Now that you have been able to participate in a semester-long mentoring opportunity think ahead to next semester. If mentoring was offered again next semester would you do it again without receiving a monetary stipend? Yes or No? Why or why not? Please explain.

\subsection{Analysis}

The NVivo 11 qualitative analysis software was used to analyze responses to the student satisfaction survey. All student responses were imported into NVivo, and the researchers read through the responses several times. The researchers individually coded and highlighted the responses to identify themes connected to the research questions (1) How does participating in the mentoring contribute to student satisfaction? (2) How does participating in photovoice and photo-elicitation contribute to student satisfaction? Due to the qualitative nature of the study and the exploratory pilot study approach, the goal of analysis for the open-ended questions was to explore potential themes within the data. As a result of the data analysis through coding and categorizing each response several themes emerged on students' perceptions of benefits and value in their participation in a mentoring program which used the photovoice approach. Additionally, student participants noted ways to improve the mentoring program as well as identified characteristics of a good mentor.

\section{Results}

\subsection{Student Perceptions: Benefits of Participation in a Mentoring Program}

Participants perceptions on the benefits of the mentoring program believed it to be an enriching learning experience that allowed for additional support which aided in goal development, accountability, and an opportunity to learn more about strategies for student success. Some example student responses are provided here.

- "Having someone to talk to about the challenges I faced as a student helped me deal with stress, made me feel cared about, and helped me develop the skill of communicating my feelings."

- "Support, staying on track, working on goals, accountability."

- "Enriched learning experience, psychosocial support, enhanced personal responsibility."

- "I have learned the value of self-worth. I have developed a good working relationship with a new mentor. I have improved my coping skills."

- "Learning how to set goals, actually think about them and strategize on them, accomplish my goals. To think more about my future and take the right pathway and steps to get there. Learning more about myself, being able to reflect on things I've accomplished and things that are obstacles."

\subsection{Student Perceptions: Benefits of Participation in Photovoice}

Participants noted they learned to identify successes and barriers to their education through photovoice but more importantly learned the power of self-expression and reflection as they were able to learn more about themselves as college students which increased their resiliency and understanding. Some example student responses are provided 
here.

- "A picture says 1,000 words; my narratives are only the beginning. Photovoice helped me realize all of what I have overcome, and I didn't give up!"

- "Taking photos and writing statements helped me relieve stress by expressing myself, recognize what parts of life were a source of stress, and recognize what parts of life to be thankful for (as in what was motivating me)."

- $\quad$ "I learned how to identify basic problems and roadblocks that prevent me from completing my educational goals and various ways to deal with those problems which greatly increases my chances of academic success."

- "I have learned to look at situations in a different point of view. I have expanded my understanding of my challenges and motivations."

\subsection{Student Perceptions: Ways to Improve the Mentoring Program}

Participants suggestions on improving the mentoring program focused entirely on ways to improve the use of photovoice during the mentoring meeting; from changing and providing more varied prompts to allow for other forms of expression. Some example student responses are provided here.

- "Simplify the assignment questions."

- "One possible way of improving the mentoring program would be including other forms of art besides photography to express the challenges and motivators of life. For example, painting, drawing, collaging, sculpting, or other forms of art. I found everything about the program to be beneficial, so there is not much I would change."

- "Use a different way other than photos to identify. Questions were similar and hard to come up with answers that were not the same from week to week."

- "As one of the assignments you could have participants identify both roadblock's preventing them from completing their goal's as well as possible solutions to those roadblocks."

\subsection{Student Perceptions: Characteristics of a Good Mentor}

- "Encouraging, reachable, and knowledgeable."

- "If more faculty/staff mentors were recruited, they would need to be patient, understanding, non-judgmental, caring, kind, and inspirational."

- "Someone to be there to support you check up on you make sure your handling college life okay. Someone that helps you if you need and can show you the resources you need to get the help you need, so you don't fail as a college student."

- "My mentor was kind, compassionate, and understanding, however, she knows how to balance that with discipline, encouragement, and reminders. The only thing I would ask for was more time."

- "Someone who is understanding, that listens, willing to help you out. One that gives guidance and advice."

\subsection{Student Perceptions: Value of Mentoring}

All but two participants would participate in the mentoring program without receiving a monetary stipend. Participants believed that having the opportunity to be mentored provided invaluable support that was not only beneficial to their education but also their personal life. Some example student responses are provided here.

- "The program helped me by keeping me accountable for my progress in school."

- "It was a great opportunity. It helped me to learn and grow. I have more confidence also when it comes to making future choices."

- "I like the support that I was given and felt like I could talk with my mentor a little bit more about home life and college life as well. It was another place for me to go and release stress or get advice if I needed it."

- "My mentor helped me believe in myself and overcome some difficult times this semester. For me, that is invaluable." 


\section{Discussion}

\subsection{Practical Significance}

The findings of this study are significant in understanding the needs of underrepresented postsecondary STEM students. Student participation in a mentoring program and photovoice project provided psychosocial support that is critical for underrepresented STEM student development, retention, persistence, and navigation of the postsecondary setting. Participants perceived the mentoring program to be an enriching experience that provided an opportunity to learn strategies critical to student success. Meza, Rodriguez, Trujillo, and Ladd-Viti (2018) conducted a study on a mentoring program for students pursuing graduate school; their findings were consistent with ours in that as a result of the mentoring program mentees reported a change in perceptions and an increase in plans for moving forward. Furthermore, participation in the photovoice project allowed for student self-expression and recognition of individual successes and barriers. Photovoice and photo-elicitation supported students' individual growth, engagement, and empowerment. Kelly, Lee, Bowen Ray, and Kandaurova (2018) found that using the photovoice method as an assignment led to increased student interest, enthusiasm, and engagement as students became active participants in their learning. Hund et al. (2018) studied the underrepresentation in STEM and the role of effective mentoring. Their findings suggest several universal characteristics of a positive and productive mentor include flexibility, communication, and trust. These characteristics are strongly aligned with our findings.

\subsection{Limitations}

This study had a few limitations which should be noted. First, the qualitative and exploratory nature of the study will limit the generalizability of the findings. Second, assessment of what mentors learned from their mentees was not undertaken and thus, it is recommended that mentor perspectives are captured in future studies. In particular, it would be important to assess if mentors reported what they perceived to be beneficial for mentees. Third, assessment of the mentors and how they assisted and advised their mentees on challenging student issues were not conducted and is recommended. Fourth, a pre-assessment survey was not required and would have helped gauge what students' perceptions were of mentoring and perceived benefits before the start of the program.

There are a number of gaps in the current understanding around mentoring and the use of photovoice which would benefit from further research. Future research should investigate this mentoring approach for students outside of STEM and/or as a method for high school career counselors to assist students in identifying appropriate educational and/or career paths. Also, future research should explore the opportunity to learn from data to offer individualized interventions and student success strategies. Lastly, future research should further consider the role of researchers, educators, and administrators in engaging historically underrepresented STEM students in sharing their successes and challenges and identifying strategies to facilitate deeper reflection, critical thinking, and subsequent empowerment for underrepresented students throughout the photo-elicitation process.

\subsection{Conclusion}

The purpose of this study was to explore a new and innovative approach to mentoring historically underrepresented STEM students, applying the photovoice methodology, to identify successes and barriers to students' educational experience. Students of color are significantly underrepresented in academia, and furthermore, issues related to the transition and retention of American Indian students are understudied in higher education-related research. Although there is existing research on historically underrepresented students (in general), including low-income and first-generation, postsecondary transition and retention challenges, much of the research has been conducted and collected on these types of students without regard for allowing students to actually participate and share their perspective. Consequently, this study takes student participation one step further by asking students to share their lived experiences and photographs of successes and barriers with their mentor while using photo-elicitation techniques to further engage them in discussing what led to their subsequent empowerment in leveraging successes or overcoming barriers. The implementation of this new approach and the results gathered from this study are important as they can inform educational leaders and postsecondary institutions serving historically underrepresented STEM students on supports and strategies that could be carried out on their campuses.

\section{Acknowledgments}

Funding for this research was supported by the U.S.A. National Science Foundation (NSF) under Grant No. 1642029. Any opinions, findings, and conclusions expressed in this material are those of the authors and do not necessarily reflect the views of the National Science Foundation. Additionally, this research was conducted and written to meet the dissertation requirements of the Doctoral program in Educational Leadership at Edgewood College (Madison, WI). The researchers would like to acknowledge the guidance and assistance of thought-provokers and cultural 
education experts including Dr. Elise Ahn, Dr. Kirsten Brown, Dr. Bonnie Duran, Dr. William Freeman, Dr. Deborah His Horse Is Thunder, Dr. Joan LaFrance, Dr. Bette Lang, Dr. Sara Jimenez Soffa, Dr. Myra Parker, and Dr. Candy Waukau Villagomez.

\section{References}

Agarwal, N., Moya, E., Naoko Yura, Y., \& Seymour, C. (2015). Participatory action research with college students with disabilities: Photovoice for an inclusive campus. Journal of Postsecondary Education \& Disability, 28(2), 243-250.

Castleden, H., \& Garvin, T. (2008). Modifying Photovoice for community-based participatory Indigenous research. Social Science \& Medicine (1982), 66(6), 1393-1405. https://doi.org/10.1016/j.socscimed.2007.11.030

Collings, R., Swanson, V., \& Watkins, R. (2014). The impact of peer mentoring on levels of student wellbeing, integration and retention: a controlled comparative evaluation of residential students in UK higher education. Higher Education(6), 927. https://doi.org/10.1007/s10734-014-9752-y

Crisp, Baker, Griffin, Lunsford, \& Pifer. (2017). Mentoring undergraduate students (1551-6970). Retrieved from

Crisp, G., Baker, V. L., Griffin, K. A., Lunsford, L. G., \& Pifer, M. J. (2017). Mentoring undergraduate students (1551-6970). Retrieved from

Crisp, G., \& Cruz, I. (2009). Mentoring college students: A critical review of the literature between 1990 and 2007. Research in Higher Education, 50(6), 525-545. http://www.jstor.org/stable/29782942

Dika, S. L., Pando, M. A., Tempest, B. Q., Foxx, K. A., \& Allen, M. E. (2015, 21-24 Oct. 2015). Engineering self-efficacy, interactions with faculty, and other forms of capital for underrepresented engineering students. Paper presented at the 2015 IEEE Frontiers in Education Conference (FIE).

Downey, G. L., Lucena, J. C., Moskal, B. M., Parkhurst, R., Bigley, T., Hays, C., . . Ruff, S. (2006). The globally competent engineer: Working effectively with people who define problems differently. Journal of Engineering Education, 95(2), 107-122. https://doi.org/10.1002/j.2168-9830.2006.tb00883.x

Engle, J., \& Tinto, V. (2008). Moving beyond access: College success for low-income, first-generation students. The Pell Institute for the Study of Opportunity in Higher Education. Washington, DC: Author.

Flynn, Duncan, K., \& Jorgensen, M. (2012). An Emergent Phenomenon of American Indian Postsecondary Transition and Retention. Journal of Counseling \& Development, 90(4), 437-449. http://dx.doi.org/10.1002/j.1556-6676.2012.00055.x

Godwin, A., Potvin, G., Hazari, Z., \& Lock, R. (2016). Identity, Critical Agency, and Engineering: An Affective Model for Predicting Engineering as a Career Choice. Journal of Engineering Education, 105(2), 312-340. http://dx.doi.org/10.1002/jee.20118

Graham, M. J., Frederick, J., Byars-Winston, A., Hunter, A.-B., \& Handelsman, J. (2013). Increasing persistence of college students in STEM. Science, 341(6153), 1455-1456. https://doi.org/10.1126/science.1240487

Guillory, \& Wolverton, M. (2008). It's about family: Native American student persistence in higher education. The Journal of Higher Education, 79(1), 58-87. https://doi.org/10.1080/00221546.2008.11772086

Guillory, R. M., \& Wolverton, M. (2008). It's about family: Native American student persistence in higher education. The Journal of Higher Education, 79(1), 58-87. https://doi.org/10.1353/jhe.2008.0001

Harkness, S., \& Stallworth, J. (2013). Photovoice: Understanding high school females' conceptions of mathematics and learning mathematics. Educational Studies in Mathematics, 84(3), 329-347. https://doi.org/10.1007/s10649-013-9485-3

Hergenrather, K., Rhodes, S., Cowan, C., Bardhoshi, G., \& Pula, S. (2009). Photovoice as community-based participatory research: a qualitative review. American Journal of Health Behavior, 33(6), 686-698. http://dx.doi.org/10.5993/AJHB.33.6.6

Huffman, T. (2001). Resistance theory and the transculturation hypothesis as explanations of college attrition and persistence among culturally traditional American Indian students. Journal of American Indian Education, 1-23.

Hund, A. K., Churchill, A. C., Faist, A. M., Havrilla, C. A., Love Stowell, S. M., McCreery, H. F., . . Scordato, E. S. (2018). Transforming mentorship in STEM by training scientists to be better leaders. Ecology and evolution, 8(20), 9962-9974. https://doi.org/10.1002/ece3.4527

Hunt, B., \& Harrington, C. (2010). The impending educational crisis for American Indians: Higher education at the 
crossroads. Indigenous Policy Journal, 21(3).

Jackson, A., Smith, S., \& Hill, C. (2003). Academic persistence among Native American college students. Journal of College Student Development, 44(4), 548-565. https://doi.org/10.1353/csd.2003.0039

Johri, A., \& Olds, B. M. (2014). Cambridge handbook of engineering education research: Cambridge University Press.

Keith, J., Stastny, S., \& Brunt, A. (2016). Barriers and strategies for success for American Indian college students: A review. Journal of College Student Development, 57(6), 698-714. https://doi.org/10.1353/csd.2016.0069

Kelly, K., Lee, S. H., Bowen Ray, H., \& Kandaurova, M. (2018). Using the photovoice methodology to increase engagement and sharpen students' analytical skills regarding cultures, lifestyles, and markets internationally Marketing Education Review, 28(2), 69-74. https://doi.org/10.1080/10528008.2018.1450093

Kolb, D. (1984). Experiential learning : Experience as the source of learning and development. Englewood Cliffs, N.J.: Prentice-Hall.

Latz, A. O. (2015). Understanding Community College Student Persistence Through Photovoice:An Emergent Model. Journal of College Student Retention: Research, Theory \& Practice, 16(4), 487-509. https://doi.org/10.2190/CS.16.4.b

Lichtenstein, G., Chen, H. L., Smith, K. A., \& Maldonado, T. A. (2014). Retention and persistence of women and minorities along the engineering pathway in the United States. Handbook of engineering education research, 107(2), 311-334.

Liou, D., Martinez, A., \& Rotheram-Fuller. (2016). "Don't Give up on Me": Critical mentoring pedagogy for the classroom building students' community cultural wealth. International Journal of Qualitative Studies in Education (QSE), 29(1), 104-129. https://doi.org/10.1080/09518398.2015.1017849

MacPhee, D., Farro, S., \& Canetto, S. S. (2013). Academic self - efficacy and performance of underrepresented STEM majors: Gender, ethnic, and social class patterns. Analyses of Social Issues and Public Policy, 13(1), 347-369. https://doi.org/10.1111/asap.12033

Meza, J. I., Rodriguez, K., Trujillo, C., \& Ladd-Viti, C. (2018). Helping Students at the Margins Get Into Graduate School: Evaluating a Multifaceted Mentoring Program. The Mentor: Innovative Scholarship on Academic Advising, 20, 26-41.

Minthorn, \& Marsh. (2016). Centering Indigenous college student voices and perspectives through photovoice and photo-elicitation. Contemporary Educational Psychology, 47(Supplement C), 4-10. https://doi.org/10.1016/j.cedpsych.2016.04.010

National Science Board. (2018). NSF Science and Engineering Indicators 2018 (NSB-2018-1). Retrieved from

Sahay, K., Thatcher, K., Núñez, C., \& Lightfoot, A. (2016). 'It's like we are legally, illegal': Latino/a youth emphasize barriers to higher education using photovoice. The High School Journal, 100(1), 45-65. https://doi.org/10.1353/hsj.2016.0020

Sheppard, S., Antonio, A., Brunhaver, S., \& Gilmartin, S. (2014). The early career pathways of engineering students: Cambridge Handbook of Engineering Education Research, A. Johri and B. Olds, Eds. New York, NY: Cambridge University Press.

Tate, Fouad, N., Marks, L., Young, G., Guzman, E., \& Williams, E. (2015). Underrepresented first-generation, low-income college students' pursuit of a graduate education: Investigating the influence of self-efficacy, coping efficacy, and family influence. Journal of Career Assessment, 23(3), 427-441. https://doi.org/10.1177/1069072714547498

Tonso, K. L. (2014). Engineering identity. Cambridge handbook of engineering education research, 267-282.

Tsui, L. (2007). Effective Strategies to Increase Diversity in STEM Fields: A Review of the Research Literature. The Journal of Negro Education, 76(4), 555-581.

Wang, \& Burris, M. (1997). Photovoice: Concept, methodology, and use for participatory needs assessment. Health Education \& Behavior, 24(3), 369-387. https://doi.org/10.1177/109019819702400309

Wilson, Z., Holmes, L., deGravelles, K., Sylvain, M., Batiste, L., Johnson, M., . . Warner, I. (2012). Hierarchical mentoring: A transformative strategy for improving diversity and retention in undergraduate STEM disciplines. Journal of Science Education and Technology, 21(1), 148-156. https://doi.org/10.1007/s10956-011-9292-5 


\section{Appendix A}

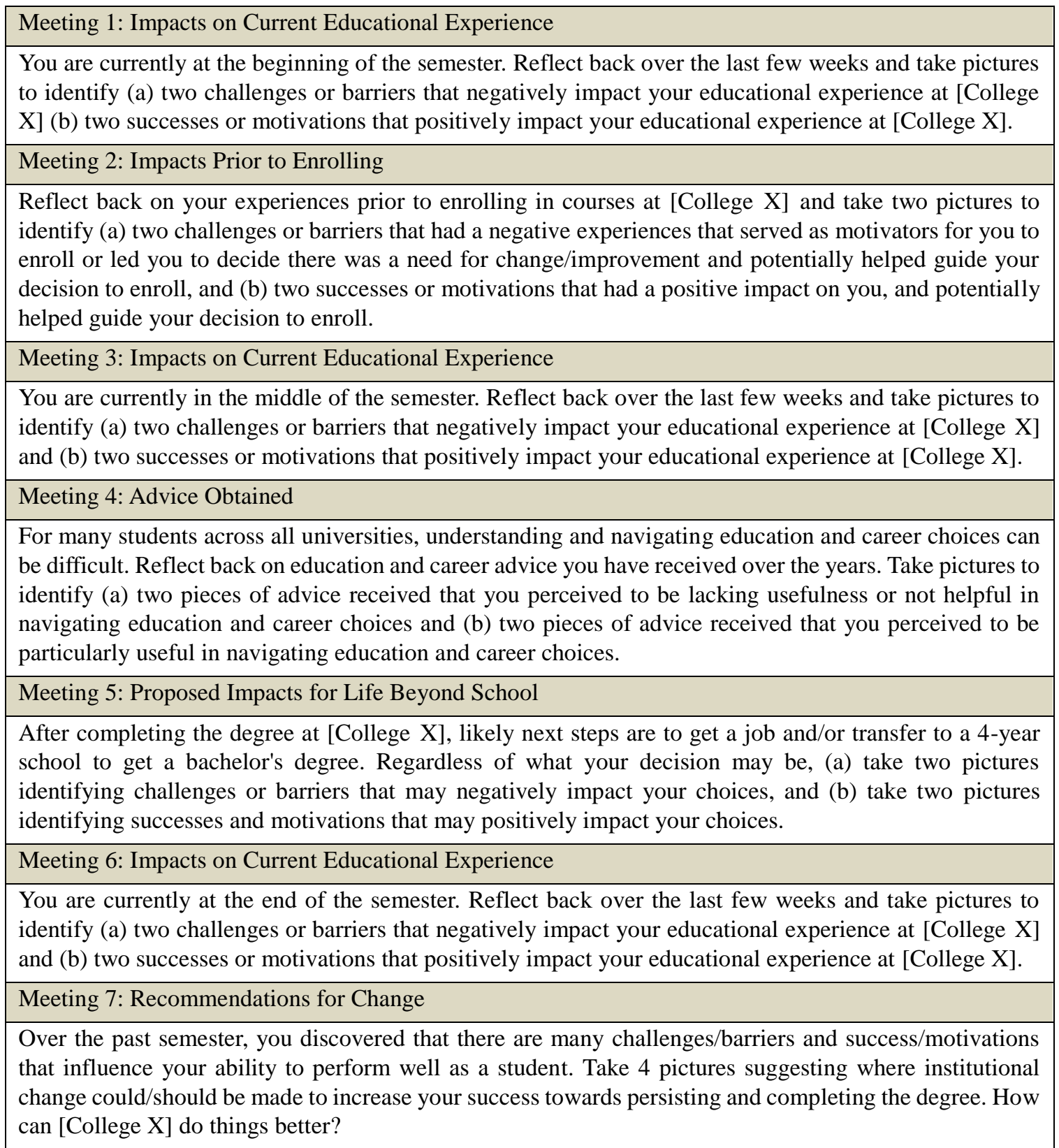

